\title{
Open Lab Heritage. El IAPH apuesta por la generación de sinergias para la innovación cultural
}

\begin{abstract}
A principios de 2016 se presentaba en la sede del IAPH el Laboratorio Abierto de Patrimonio (Open Lab Heritage), una línea de trabajo diferente para adaptarse a las nuevas realidades y necesidades de los profesionales del patrimonio. El primer objetivo del recién constituido Laboratorio es, a partir de los modelos de laboratorios existentes más afines a su carácter de servicio público, definirse como espacio de sinergias donde crear redes de profesionales de los sectores patrimonial, tecnológico y creativo.
\end{abstract}

Centro de Formación y Difusión del IAPH

URL de la contribución <www.iaph.es/revistaph/index.php/revistaph/article/view/3747>

En términos generales, los laboratorios abiertos son espacios de encuentro entre profesionales interesados en temas o proyectos concretos que posibilitan el cruce y colaboración entre dichos grupos. La actividad de todos ellos en conjunto es lo que conforma de hecho los open lab. Es una metodología orientada a la investigación, la apropiación y desarrollo, en el que un grupo de personas con un interés común (tema convocante) y desde perspectivas diferentes (grupo interdisciplinar). El compartir, la colaboración y la escucha son las premisas de este método.

El Open Lab Heritage facilitaría el intercambio de conocimiento entre el sector cultural y el sector creativo relacionado con las TIC y las industrias creativas. De manera que se concibe como un espacio de encuentro donde generar sinergias y materializar oportunidades de cola-

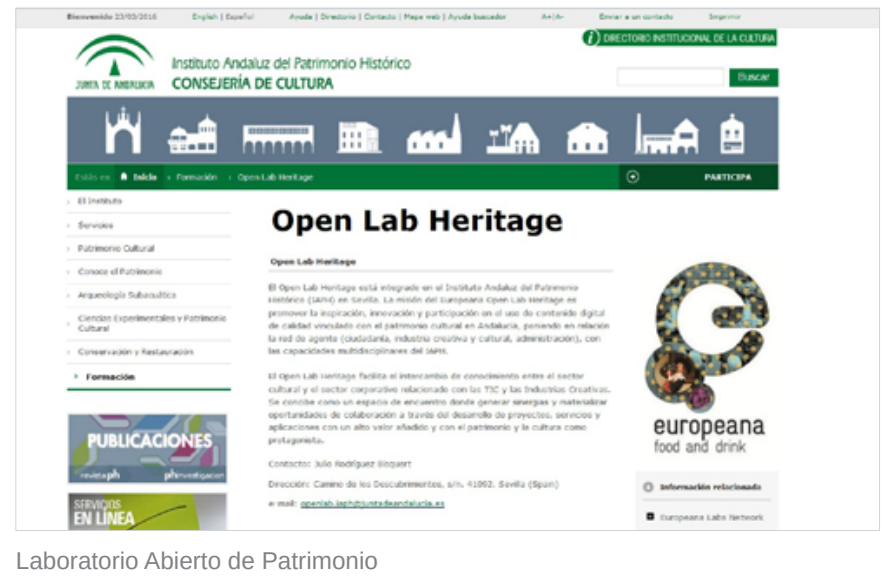

boración y negocio a través del desarrollo de proyectos, servicios y aplicaciones con un alto valor añadido y con el patrimonio y la cultura como protagonista. Desde esta óptica, las capacidades multidisciplinares y el conocimiento producido en el IAPH, con voluntad de servicio público, se pondrían en relación con la red de agentes: ciudadanía, industria creativa y cultural, y administración. Al mismo tiempo, en una relación de feedback, el IAPH tendría la oportunidad de incorporar los contenidos generados en estos encuentros.

Esta nueva línea de trabajo del IAPH tiene como antecedentes que la inspiran el proyecto Ambrosía (Food \& Drink) de la Fundación Europeana, en el que participa. Europeana es la biblioteca digital europea, de acceso libre, que reúne fondos de reconocidas instituciones culturales de los 28 Estados miembros de la Unión Europea. Uno de los valores de Europeana es que el contenido sea "utilizable", es decir, para que la cultura sea un catalizador del cambio social y económico, debe ser posible que sea fácilmente utilizable y de fácil acceso para que las personas la aprovechen, desarrollen y compartan.

Para Europeana su "misión es desbloquear el patrimonio cultural de Europa, aprovechando la tecnología para ayudar a las personas a hacer cosas nuevas y transmitirlas". Europeana se quiere posicionar como una plataforma que reúne a personas y empresas que desean ver, usar y reutilizar el patrimonio, con las personas y organizaciones que tienen patrimonio para compartir. Desde estas premisas, incorporan la fórmula en 2014 de 


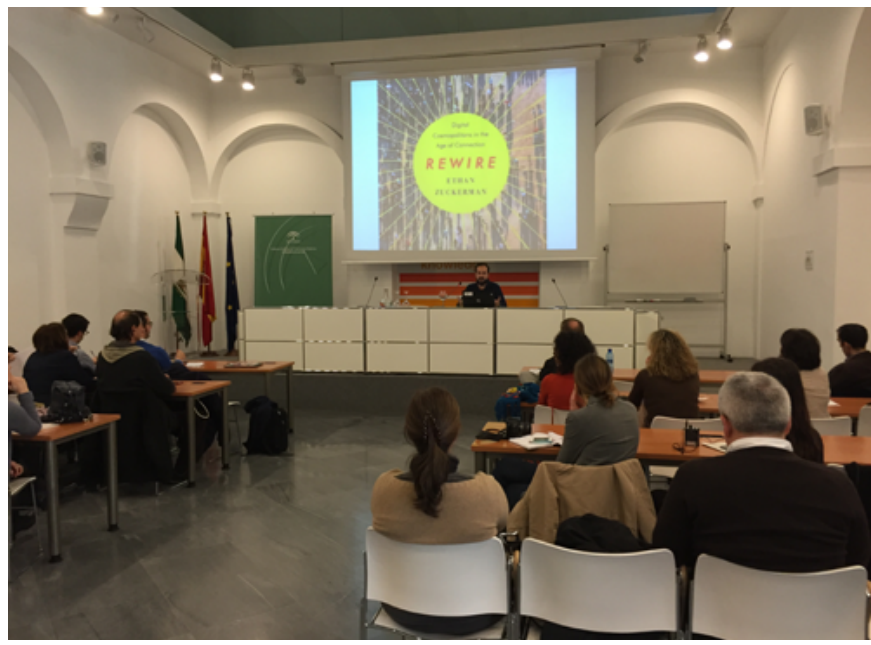

Marcos García Cristóbal, Medialab-Prado | foto Fondo Gráfico IAPH, titular de todas las imágenes de la contribución

los laboratorios creativos o el llamado proyecto de experimentación digital Europeana Open Labs.

El proyecto Ambrosía es una materialización de esta estrategia. Su principal objetivo: promover la reutilización de los recursos digitales disponibles a través de Europeana centrándose en esta ocasión en el rico y variado patrimonio europeo relacionado con la comida y la bebida con la finalidad de implicar a las industrias creativas, a las organizaciones culturales, a la industria de la alimentación y al público en general en la utilización de los contenidos digitales relacionados con el mismo. El papel del IAPH en el marco del proyecto ha consistido, por un lado, en la provisión de contenidos digitales y, por otro, en la colaboración con las industrias creativas para el desarrollo de aplicaciones comerciales y la validación de su efectividad, viabilidad e impacto.

En el marco del proyecto Ambrosía, el IAPH organizó en 2015, junto a la Universidad de la Sapienza de Roma, un concurso en el que se presentaba a los participantes el reto de interrelacionar el patrimonio gastronómico, la producción agroalimentaria y el sector creativo, teniendo como fuente los objetos digitales disponibles en la biblioteca digital de Europeana.

El acto de entrega del premio, celebrado el pasado 29 de enero en la sede del IAPH en Sevilla, se hizo coincidir con

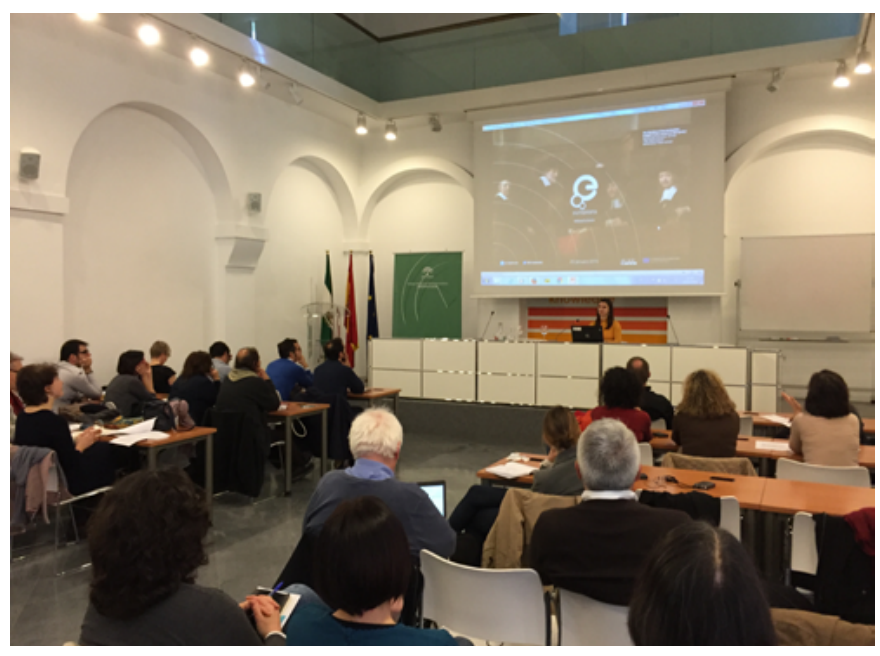

Milena Popova, Fundación Europeana, durante la presentación del Laboratorio Abierto de Patrimonio

la jornada de debate "Europeana Open Labs: Economía digital del patrimonio cultural y las industrias creativas" en la que los diferentes participantes (entre otros, el proyecto Medialab-Prado, Platoniq/Goteo, Europeana Open Labs y Andalucía Lab) presentaron diferentes modelos de gestión y financiación de laboratorios abiertos.

En el panel de presentación de los Europeana Open Labs se dieron a conocer el Open Lab Cultura de Roma, el AALTO Fab Lab de Helsinki, y por primera vez de forma oficial el emergente Open Lab Heritage del Instituto Andaluz del Patrimonio Histórico.

Confiamos que esta nueva línea de trabajo del IAPH amplíe sus posibilidades de interaccionar con la sociedad, y con sectores profesionales concretos como los vinculados a la cultura, el patrimonio cultural y las industrias creativas, revirtiendo al mismo tiempo en la innovación cultural y la mejora de la situación de la sociedad. 